\title{
Re-thinking democracy, development and social justice in education: connecting global, national and local challenges
}

\author{
Fazal Rizvi ${ }^{1}$ Moon Suk Hong ${ }^{2}$
}

Published online: 19 June 2019

(c) Education Research Institute, Seoul National University, Seoul, Korea 2019

The papers in the Special Issue of Asia Pacific Education Review were initially presented at the 2018 International Conference on Education Research (ICER) held at Seoul National University. The conference brought together leading scholars from around the world to consider issues of democracy, development and social justice in education. The robust discussions that followed demonstrated again how these concepts remain pertinent to educational policy and practice, but equally, they are highly contested. In a world that is increasingly globally interconnected and interdependent, it is clear that new ways of thinking about these concepts and the issues they raise are needed.

In an era in which the assumptions of colonialism are no longer accepted, it is important to consider how these assumptions continue to shape our thinking about issues of democracy, development and social justice in education, and how they might be abandoned and displaced culturally, epistemically and politically. The question of how the idea of development, for example, might be re-imagined in decolonial terms is especially important in education to assess and create the possibilities of reform and to overcome the obstacles that are inherent in attempts to translate them into effective practice. These attempts invariably involve not only technical solutions but more fundamentally issues of ethics and politics.

The papers in this Special Issue are arranged in four overlapping categories. In Section 1, a range of conceptual issues concerning the notions of democracy, development and social justice are examined. The first paper, by Hyo-Je Cho, invites us to rethink the ideas of democracy and human rights on the 70th anniversary of the Universal Declaration of Human Rights. In the next paper building upon her extensive work on the human capabilities' paradigm, Melanie

\footnotetext{
$\triangle$ Fazal Rizvi

frizvi@unimelb.edu.au

Melbourne University, Parkville, Australia

2 Seoul National University, Seoul, South Korea
}

Walker interrogates the complex relationship between the notions of epistemic justice and democracy in education. The next paper, by Shelden Shaeffer, focuses on the notion of inclusive education and its fundamental importance for conceptualizing social justice. And, finally, in this section, William C. Smith and Aaron Benavot employ their extensive knowledge of global monitoring mechanisms to put forward a strong argument about the importance of accountability in open democratic societies.

The second section in this Special Issue includes two papers that re-examine and re-imagine the idea of development and its complex relationship to education, particularly against the backdrop of UNESCO's Sustainable Development Goals. Basing their analysis on the works of Goulet, Sen and Freire, Sung Sang Yoo and his colleagues attempt to re-imagine the idea of development in terms of its intrinsic relationship to education, and the role that education must play in working towards the goal of social justice. In the next paper, Leon Tikly draws our attention to the innovative conceptual thinking currently taking place in Africa, around attempts by its educational systems to better understand its 'postcolonial' condition and to work towards an agenda of decolonizing education through transformative sustainable development.

The next four papers in Section 3 explore the complex and dynamic links across global, regional, national and local politics in education. Myanmar is the focus of two of these papers, one by Moon Suk Hong and Hani Kim and the other by Thein Lwin. Hong and Kim examine the historical significance of student activism in contemporary Myanmar, in attempts to democratize the nation's educational and political institutions. It put forward a strong argument about the importance of building democracy in higher education institutions in Myanmar and beyond. The focus of Thein Lwin's paper is much broader. From a civil society perspective, it discusses the complex relationship among justice, national education and local realities in Myanmar. In the next paper, Sun Kim and Dong-Joon Jung address the ways in which it 
might be possible to reconcile the ideological challenges of educational reform in the two Koreas, currently structured around the competing discourses of nationalism. And, finally, in this section, Evelyn Romboao examines the integration of technology in schools in the Philippines and the ways in which this reproduces patterns of social and educational inequality, thus undermining claims of social justice.

The final section of this Special Issue is more explicitly normative and addresses the political and ethical issues that systems of education now face. Wonseok Kim's paper takes a critical look at the discourse of political neutrality in South Korea, linking this discourse to what he calls 'the crisis of democratic education'. Kenneth King seeks to unravel the complex and changing relationship between democracy and education. He shows how education takes place not only in a formal setting but increasingly in the media, which has become a major site of the political formation of students. The paper by Liz Jackson is also about the political formation of students. It considers the moral imperative of 'learning to live together'. She suggests that this now involves navigating the complex space in which the global, national and local exist in an uneasy and shifting relationship with each other. In the final paper, Fazal Rizvi also points to the ethical and educational challenges of the increasing levels of both global interconnectivity and nationalisms fearful and deeply suspicious of the unassailable global march towards cultural diversity and exchange.
Each of these papers in its own way raises issues that are of profound importance to educational systems around the world. Going forward, these issues are likely to become more urgent. Each author is convinced of the importance of better understanding the nature of the complex relationships among global, national and local challenges. Such is this complexity however that none of the authors claims to present complete solutions to our contemporary problems, but each does hope to have provided analyses which the readers of this Special Issue might be able to consider thoughtfully and creatively. We hope they will give rise to robust discussions, similar to those that took place at the Conference and in the process of preparing this Special Edition. We have had great pleasure in conceptualizing the themes and issues explored in this Special Issue, and in interacting with colleagues around the world over the past 6 months. We are most grateful for their cooperation.

Publisher's Note Springer Nature remains neutral with regard to jurisdictional claims in published maps and institutional affiliations. 